\title{
Capsule Commentary on Huskamp et al., Effects of Global Payment and Accountable Care on Tobacco Cessation Service Use: An Observational Study
}

\author{
Jeffrey L. Jackson, M.D. M.P.H. \\ Zablocki VAMC, Milwaukee, WI, USA. \\ J Gen Intern Med 31(10): 1213 \\ DOI: $10.1007 / \mathrm{s} 11606-016-3811-2$ \\ (c) Society of General Internal Medicine 2016
}

$\mathrm{T}$ obacco use is the leading cause of preventable death and disability in the US. Unfortunately, despite decades of smoking cessation effort, $18 \%$ of US adults smoke. ${ }^{1}$ In this study, Huskamp and colleagues ${ }^{2}$ found that an Alternative Quality Contract, in which accountable care organizations receive incentives for improving care performance on 64 measures, reduced smoking (from 2.02 to $1.87 \%$ ). This is despite the fact that tobacco cessation was not 1 of the 64 measures of care. The authors posit that a multi-year global payment contract incentivizes tobacco cessation as an intervention that can potentially lower future disease burden. The authors also suggest that including tobacco cessation as a specific metric could create even stronger incentives.

There are a number of approaches that have been shown to reduce smoking. Patients are more likely to quit smoking when it is recommended by their primary care provider. Unfortunately, the percentage of patients receiving this advice from their providers is low, only about $27 \%$. Interventions that incentivize the primary care provider to increase smoking cessation efforts might reduce smoking, though this is unproven. Interventions that combine pharmacotherapy and behavioral support have been shown to reduce smoking more than minimal interventions or usual care. ${ }^{3}$ This would suggest that beyond merely advising patients to quit, primary care providers are going to be most effective in settings in which they deliver both pharmacotherapy and behavioral support. In addition, direct financial incentives to patients also improve rates of smoking cessation, at least for as long as the incentives are in place. ${ }^{4}$ These incentives are typically provided by either the employer or the patient's health insurance carrier. Other studies have found that gaining insurance coverage leads to reduced rates of smoking. ${ }^{5}$ This would suggest that providing insurance to the uninsured, bundling into the insurance coverage incentives for both providers and patients to reduce smoking and paying for both pharmacologic and behavioral interventions may optimize tobacco cessation. Future studies need to examine the impact of combining these interventions. It could be that they are additive, multiplicative or there is no additional benefit.

Corresponding Author: Jeffrey L. Jackson, M.D. M.P.H.; Zablocki VAMC, Milwaukee, WI, USA (e-mail:jjackson@mcw.edu).

Compliance with ethical standards:

Conflict of Interest: The author has no conflicts of interest with this article.

\section{REFERENCES}

1. King BA, Dube SR, Tynan MA. Current tobacco use among adults in the United States: Findings from the National Adult Tobacco Survey. Am J Public Health. 2012;102(11):e93-e100.

2. Huskamp HA, Greenfield SF, Stuart EA, Donohue JM, Duckworth K, Kouri EM, Song Z, Chernew ME, Barry CL. Effects of global payment and accountable care on tobacco cessation service use: An observational study. J Gen Intern Med. 2016. doi:10.1007/s11606-016-3718-y.

3. Stead LF, Koilpillai P, Fanshawe TR, Lancaster T. Combined pharmacotherapy and behavioural interventions for smoking cessation. Cochrane Database Syst Rev. 2016;3, CD008286. doi:10.1002/14651858.CD008286. pub3.

4. Cahill K, Hartmann-Boyce J, Perera R. Incentives for smoking cessation. Cochrane Database Syst Rev. 2015;(5):CD004307.

5. Bailey SR, Hoopes MJ, Marino M, Heintzman J, O'Malley JP, Hatch B, Angier H, Fortmann SP, DeVoe JE. Effect of gaining insurance coverage on smoking cessation in community health centers: A cohort study. J Gen Intern Med. 2016. doi:10.1007/s11606-016-3781-4.

Published online July 20, 2016 